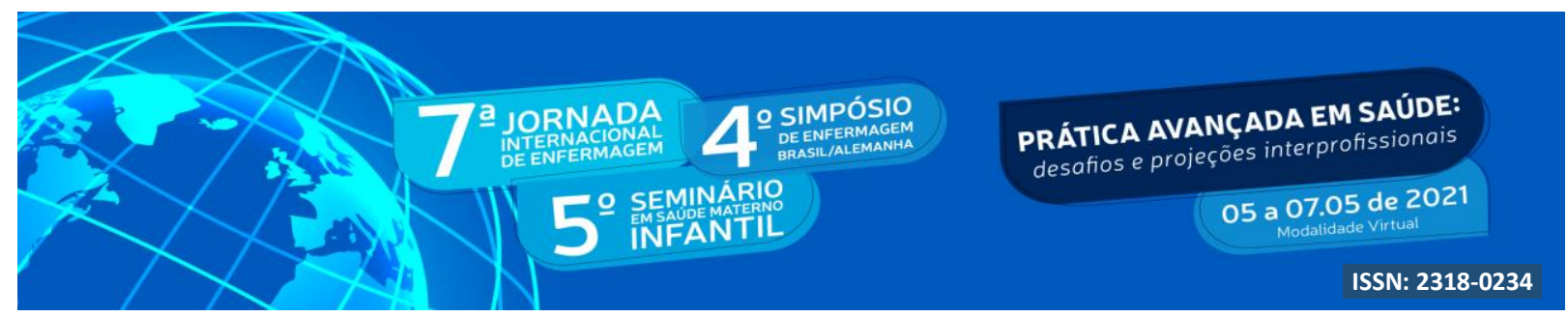

DOI: http://doi.org/10.48195/jie2021-077

\title{
CATETERISMO VESICAL DE DEMORA: EDUCAÇÃO E ORIENTAÇÃO DOMICILIAR PARA O CONTROLE DA INFECÇÃO URINÁRIA
}

\author{
Julieta Scheidt Carneiro'; ${ }^{1}$ Job Tolentino Junior ${ }^{2}$
}

\begin{abstract}
RESUMO
A infecção do trato urinário é a segunda infecção mais relacionada a assistência à saúde adquirida em hospitais. O crescimento bacteriano inicia-se após a instalação do cateter de demora com uma incidência de 30 a $50 \%$ no Brasil. O objetivo da pesquisa é promover o controle de infecção nos pacientes portadores de sonda vesical de demora através da promoção e educação em saúde, no ambiente domiciliar no Estado do Rio de Janeiro. Foram coletados dados através do questionário estruturado de 61 pacientes atendidos na atenção básica de saúde, no período de fevereiro de 2021, de caráter qualitativo e quantitativo. Foram analisados estudos através das bases de dados científicos. Considerase a necessidade de educação em saúde uma estratégia no qual o enfermeiro é um facilitador promovendo o autocuidado com abordagens que objetivam a compreensão e participação dos pacientes reduzindo as infecções urinárias.
\end{abstract}

Palavras-chave: Comunidade; Cateterismo Urinário; Atenção Primária

\begin{abstract}
Urinary tract infection is the second most health care-related infection acquired in hospitals. Bacterial growth begins after the installation of the indwelling catheter with an incidence of 30 to 50\% in Brazil. The objective of the research is to promote infection control in patients with delayed bladder catheters through health promotion and education, in the home environment in the State of Rio de Janeiro. Data were collected through the structured questionnaire of 61 patients treated in primary health care, in the period of February 2021, of a qualitative and quantitative character. Studies were analyzed using scientific databases. The need for health education is considered to be a strategy in which the nurse is a facilitator promoting self-care with approaches that aim at understanding and participating patients by reducing urinary infections.
\end{abstract}

Keywords: Community; Urinary catheterization; Primary attention

${ }^{1}$ Pós Graduação de Controle de Infecção em Assistência em Saúde (CIAS) Universidade Federal Fluminense. Email: julscheidt@hotmail.com

${ }^{2}$ Orientador. PhD em Geociências, Centro Universitário Redentor (UniRedentor),Centro de Tecnologia Mineral (CETEM-RJ) / laboratório de Argilas Aplicadas (LAA), Universidade Federal Fluminense (UFF) / Núcleo de Pesquisa e Extensão em Educação e Saúde Comunitária (NUPEESC) / Grupo Saúde Integral da Mulher e do Recém Nascido / Escola de Enfermagem Aurora de Afonso Costa - EEAAC/UFF / Curso de Controle de Infecção em Assistência À Saúde (CIAS). E-mail: jobtjr2000@yahoo.com 


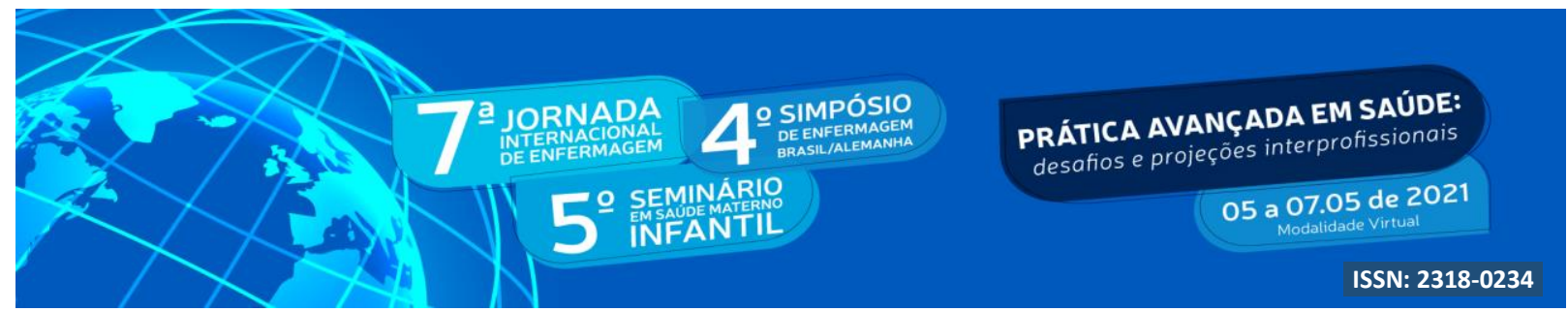

\section{INTRODUÇÃ̃O}

O Controle de Infecção nos pacientes portadores de cateterismo de demora, têm sido um grande desafio para assistência de enfermagem na atenção básica. Dentre os desafios estão a educação e a orientação desses pacientes bem como seus cuidadores.

Para Abegg e Silva (2011), a infecção do trato urinário é uma doença clínica multifatorial com necessidade de acompanhamento epidemiológico, medidas educacionais e preventivas focada na redução ou controle das taxas de infecção através da sensibilização da clientela assistida.

Ribeiro (2011), define infecção do trato urinário como: a inflamação das vias urinárias que apresentam sintomas associados e presença de bactéria na urina e representam um grave problema de saúde pública.

A infecção do trato urinário é considerada a segunda infecção relacionada à assistência à saúde mais prevalente em hospitais norte-americanos. No Brasil, a infecção do trato urinário é responsável por 30 a 50\% das infecções adquiridas em hospitais gerais (BRASIL, 2017). O principal fator de risco relacionado à infecção do trato urinário é a realização do cateterismo vesical de demora.

O cateter vesical de demora é indicado em pacientes com grave lesão medular, politraumatizados, controle do volume e débito urinário, conforto para pacientes terminais, pacientes com obstrução do trato urinário, pós-operatório de cirurgias urológicas, ortopédicas, e ginecológicas e/ou outras cirurgias.

O cateterismo vesical de demora é um procedimento invasivo no qual é inserido um cateter uretral até a bexiga, pelo enfermeiro habilitado conforme a Lei $n^{0} 7.498 / 1986$, que dispõe sobre o Exercício Profissional da Enfermagem (BRASIL, 2012).

Assim, o enfermeiro que executa o procedimento de cateterização vesical de demora é responsável por avaliar o sistema de drenagem urinária, e a identificação de sinais e sintomas de infecção do trato urinário. Tão importante quanto o conhecimento e a técnica, são a habilidade e a competência para compreender a experiência de cuidar (BRASIL, 2017; COFEN, 2013).

O Controle de infecção no trato urinário nos paciente com cateterismo vesical de demora em domicílio, são predominantemente o controle das infecções recorrentes que se dá através da aderência e a realização de cuidados adequados do próprio paciente ou cuidador. 


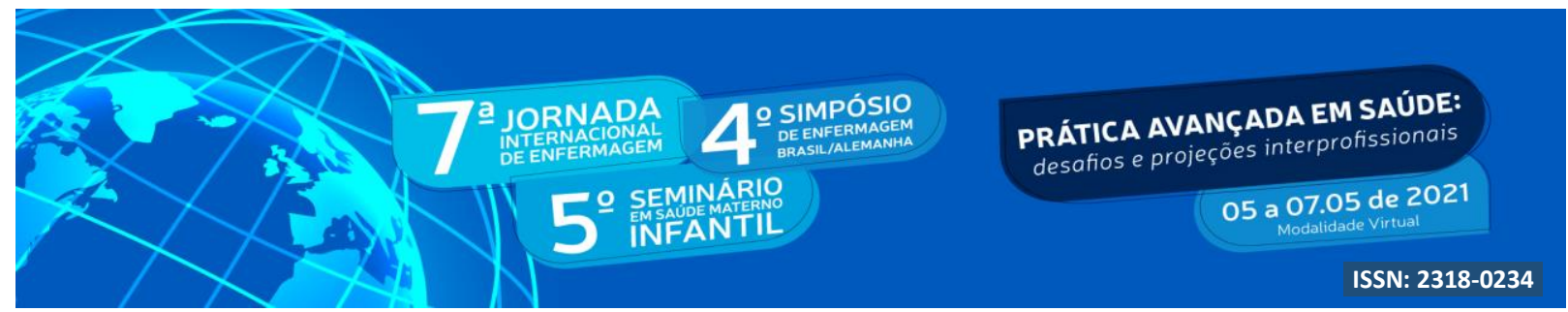

A educação em saúde é um processo baseado em princípios críticos e reflexivos nos quais auxilia a comunidade na participação ativa contribuindo para a promoção e prevençao da saúde através da vivência do próprio paciente (SILVA et al, 2013).

A pesquisa realizada no Estado do Rio de Janeiro, evidenciou a necessidade de se repensar na educação e promoção da saúde desses pacientes no que se refere ao uso de cateterismo vesical de demora no ambiente domiciliar com intuito na redução das infecções urinárias recorrentes.

\section{OBJETIVO}

Promover através da educação em saúde no ambiente domiciliar o controle de infecção urinária nos pacientes portadores de sonda vesical de demora.

\section{METODOLOGIA}

Trata-se de estudo observacional de caráter quantitativo e qualitativo, com amostragem de dados coletados nos bancos de dados públicos em uma unidade básica de saúde no Município de São Gonçalo no Estado do Rio de Janeiro.

A amostragem ocorreu no período de fevereiro de 2021, através de um questionário estruturado com base nos prontuários dos pacientes portadores de cateter vesical de demora atendidos na unidade básica de saúde. O referido estudo não necessita de trâmites no Comitê de Ética e Pesquisa, pois não fere a Resolução nº466/12 e Resolução 510/16 do Conselho Nacional de Saúde e Ministério da Saúde, Artigo 1 Parágrafo único do Comitês de Ética em Pesquisa e da Comissão Nacional de Ética em Pesquisa.

Os estudos foram selecionados por meio de busca eletrônica nas seguintes bases de dados: Literatura Latino-Americana e do Caribe em Ciências da Saúde (LILACS), Biblioteca Virtual da Saúde (BVS) e Base de Dados em Enfermagem (BDENF). Utilizou os seguintes Descritores em Ciências da Saúde (DeCS): "Comunidade"; "Cateterismo Urinário"; "Atenção Primária”.

Os critérios de inclusão para seleção dos artigos foram: textos completos, disponíveis online, publicados em 2010 a 2021, nos idiomas português e inglês. Foram excluídos os artigos que fugiram à temática propostas.

\section{RESULTADOS E DISCUSSÃO}

No período de fevereiro de 2021, 61 pacientes foram atendidos na unidade básica de Saúde no Município de São Gonçalo, no Estado do Rio de Janeiro, no ambulatório de sonda, 


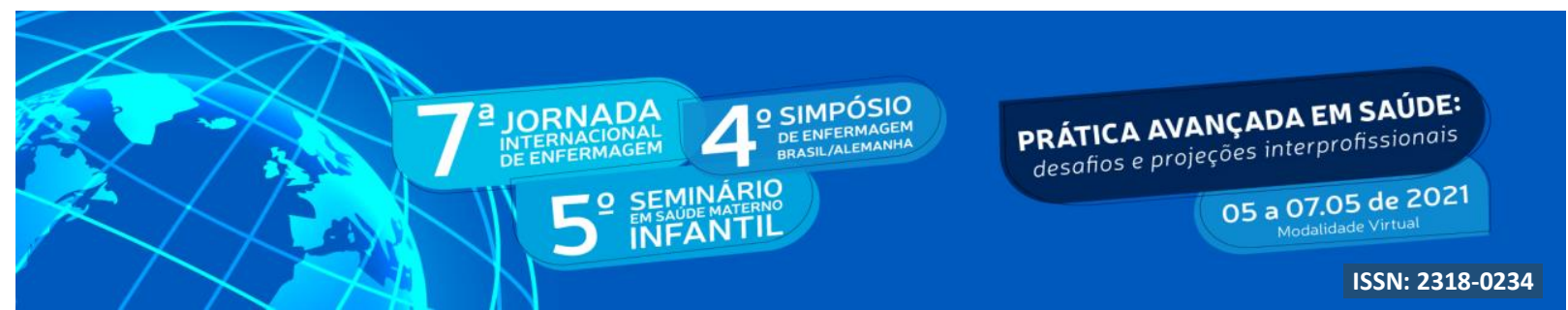

mostrou que a maior incidência do uso de cateter vesical de demora relacionado ao gênero, idade e procedência, foi em homens com um percentual de $66,6 \%$ em relação ao gênero feminino, com relação a idade, apresentou-se um percentual de 43,2\% com idade mínima de 60-70 anos, a maioria com procedência do serviço público como mostra a figura 1 e figura 2.

Estudos apontam que o gênero e a idade são fatores importantes na ocorrência de infecção do trato urinário em pacientes com idade abaixo de 65 anos, no gênero feminino, devido alterações anatômicas e funcionais relacionadas ou não a multiparidades, infecções recorrentes e menopausa, outro fator determinante está relacionado ao comprimento da uretra, sua localização por estar mais próxima da região perineal favorecendo as enterobactérias (OLIVEIRA et al, 2010).

No gênero masculino, foi observado que a incidência de infecção do trato urinário é menor por apresentar uretra longa e pela ação antibacteriana do líquido prostático. Em relação ao uso do dispositivo de sistema fechado, foi observado que $63,7 \%$ apresentou alguma infecção relacionada a anormalidade urológica como hiperplasia prostática dentre outras. A figura 1 a seguir, ilustra a distribuição por gênero e idade.

Figura 1- Distribuição por gênero, idade

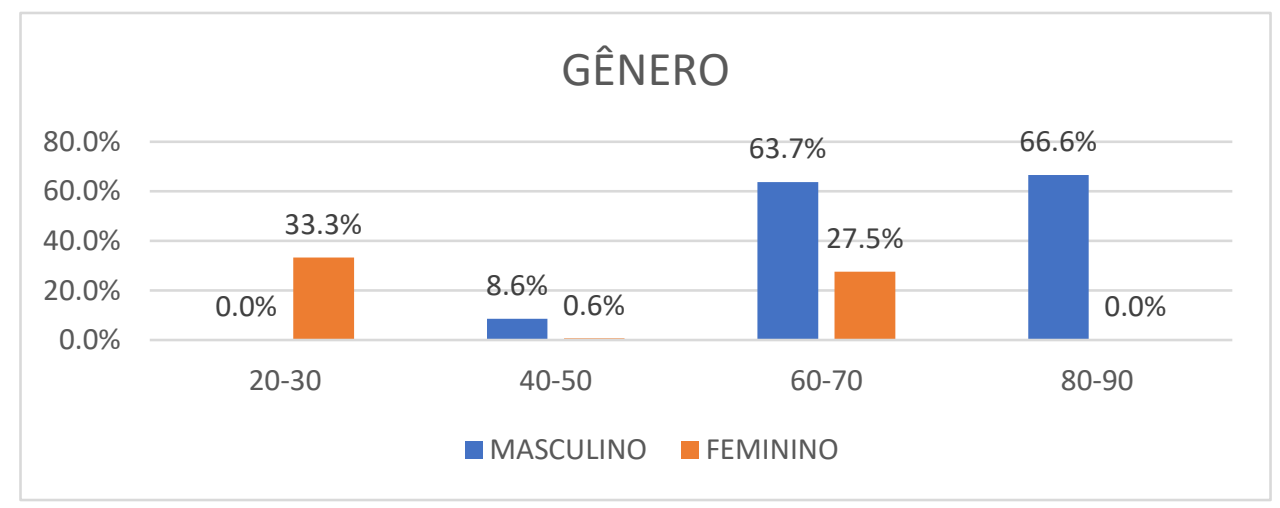

Fonte: Amostragem da pesquisa na unidade de atenção básica no Município de São Gonçalo no período de fevereiro de 2021.

Em relação a figura 2 que retrata a distribuição da procedência por instituição particular ou pública, pode se observar que 43,2\% dos idosos com 60-70 anos, utilizam o serviço de saúde pública com mais frequência relacionado ao uso do cateter vesical de demora, portanto neste contexto está relacionado ao fator socioeconômico da população do município de São Gonçalo, no Estado do Rio de Janeiro, pelo mesmo oferecer este serviço à população 


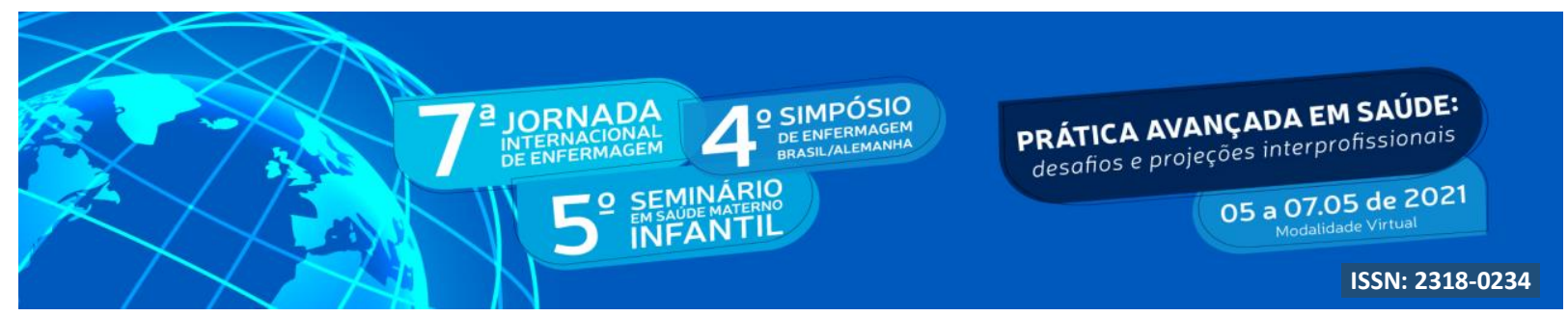

Figura 2- Distribuição da procedência por instituição particular ou pública

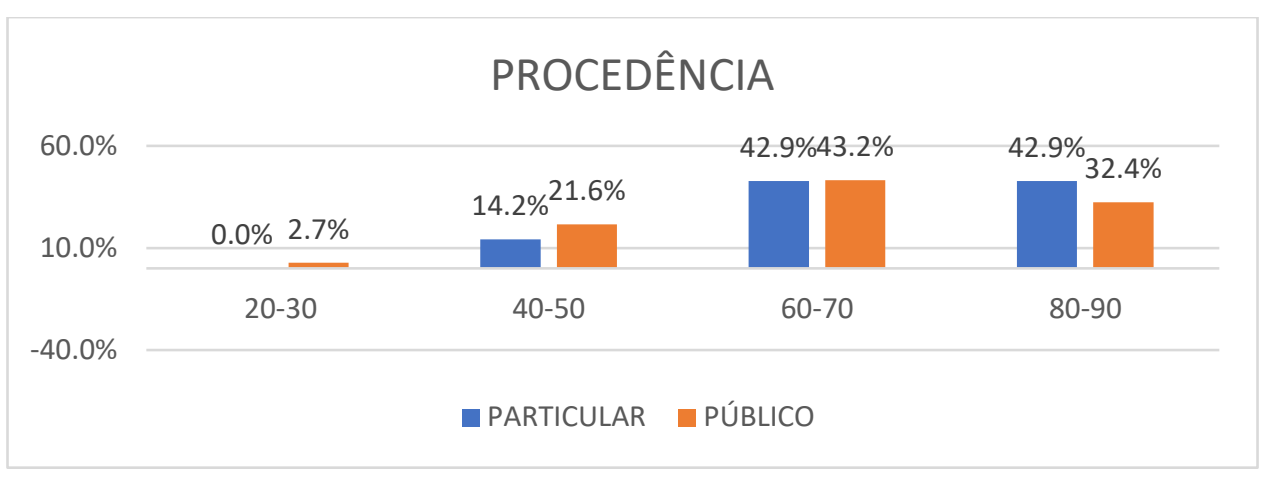

Fonte: Amostragem da pesquisa na unidade de atenção básica no Município de São Gonçalo no período de fevereiro de 2021.

Muitos estudos demonstram que a população idosa vem crescendo e com isto, as comorbidades também aumentam, gerando muitas internações principalmente por insuficiência renal aguda, insuficiência cardíaca e entre outras doenças. Dentre as doenças de base a Hipertensão apresentou-se em 15\% dos pacientes, diabetes (14\%), hiperplasia prostática (12\%), Nefropatia (11\%) e apresentam 2 comorbidades (8\%), e em algum momento apresentaram infecção bacteriana levando ao uso de antibióticos e até mesmo internações a seguir na figura 3.

Para Freitas (2010), as uroculturas são padrão ouro, no qual foi observado em seu estudo a maior prevalência de Escherichia Coli com (26\%), Pseudomonas Aeruginosa (17\%), Klebsiella Pneumoniae (13\%) e por último Proteus Mirabilis (10\%). Oliveira (2009), em seu estudo, identificou que 66,7\% dos pacientes tinha indicação de uso de Ciprofloxacino, e o uso isolado $(11,1 \%)$ e associado a outros antibióticos $(22,2 \%)$ da Vancomicina, fato relacionado à infecções acometidas em ambiente hospitalar.

A enfermeira da atenção básica, têm um papel fundamental no controle da infecções na atuação da colocação ou manutenção do dispositivo, afirmando que a adoção de boas práticas de segurança pautadas em protocolos assistenciais reduzem significativamente esses danos.

Neste contexto, a educação do paciente em uso do cateter vesical de demora é uma estratégia que potencializa o autocuidado favorecendo para promoção da qualidade de vida. 


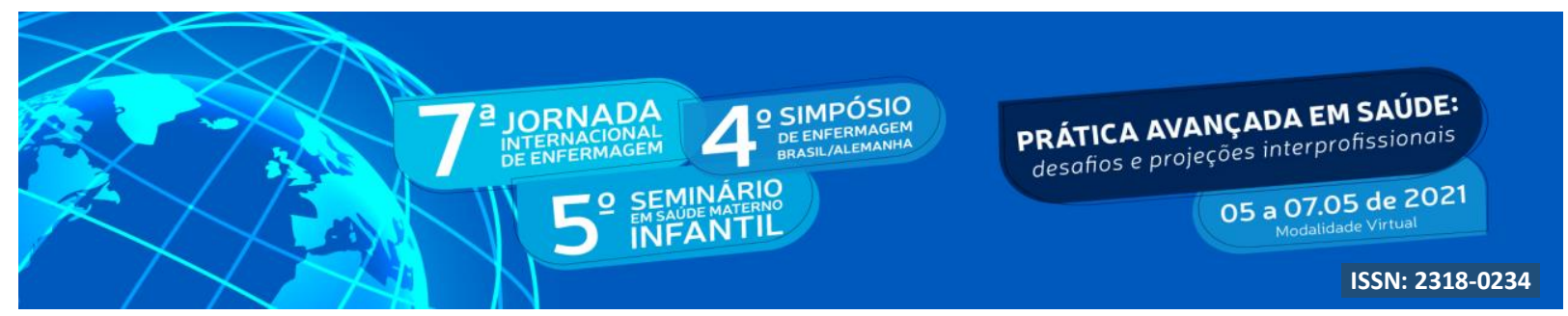

Figura 3- Distribuição dos pacientes segundo sua comorbidade

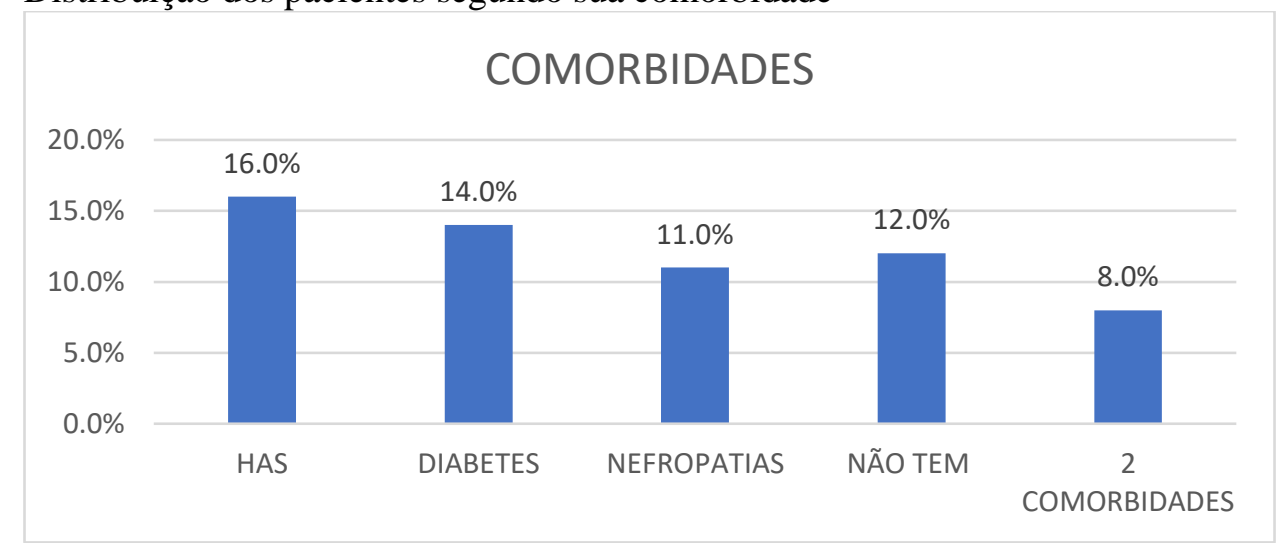

Fonte: Amostragem coletados da pesquisa na unidade de atenção básica no Município de São Gonçalo no período de fevereiro de 2021.

A inserção do cateter vesical de demora é competência do enfermeiro que deve estar habilitado e capacitado com conhecimento da anatomia para identificar resistência na passagem do dispositivo na uretra, interromper o procedimento e garantir o encaminhamento ao médico, quando necessário (COFEN,2013). Suas principais indicações são para pacientes com obstrução crônica, disfunção vesical (bexiga neurogênica), hiperplasias prostáticas com uma taxa de $15 \%$ conforme a tabela 1, drenagem vesical após cirurgias urológicas, ginecológicas que restrinjam o paciente em pós operatório, medida da diurese, conforto para pacientes com incontinência urinária.

Segundo Ercole et al. (2013) e Carlesso e Basso (2015), relatam em seus estudos que o cateterismo vesical de demora é amplamente utilizado em várias situações clínicas, mesmo apresentando complicações no decorrer do uso.

No entanto, o enfermeiro têm um papel importante na educação, promoção e prevenção das complicações e principalmente na redução das infecção do trato urinário, instruindo ao paciente quanto a higienização íntima com água e sabão, fixação da bolsa coletora abaixo da cintura próximo do joelho, aumento da ingesta hídrica, uso da medicação conforme prescrição médica e os horários.

Conforme Cologna (2011), a cistostomia é uma incisão cirúrgica realizada uma derivação vesical supra púbica no qual se cria um trajeto alternativo na bexiga para o esvaziamento da urina, sua indicação são pacientes que apresentam estenose de uretra, trauma uretral e obstrução do colo vesical. Já a sua contra indicação são para pacientes que apresentam tumores malignos de bexiga. 


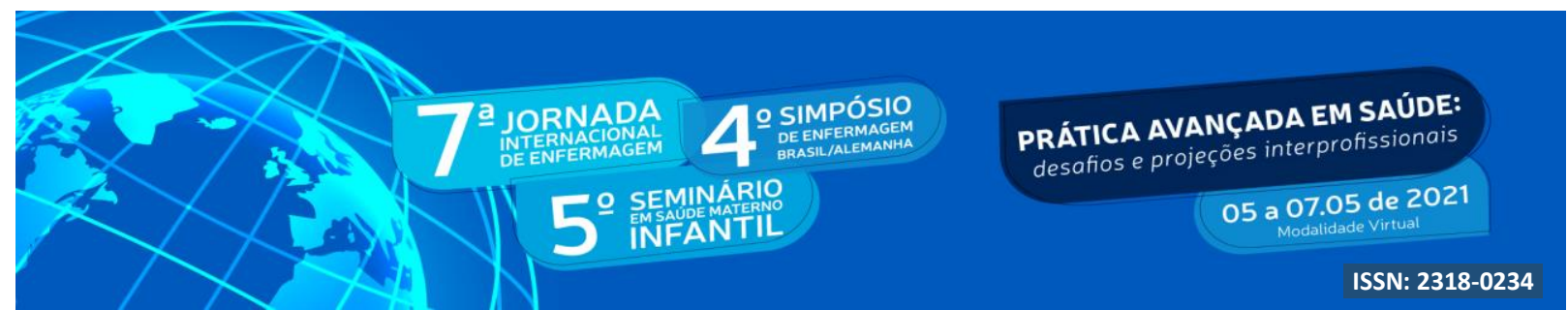

Quanto ao tempo de permanência, observou-se que a predominância de troca do cateter foi de 30/30 dias, como retrata na tabela 1 e o mesmo deve ser monitorado de acordo com as condições clínicas.

Brasil (2017), dispõe que o tempo de permanência ou frequência de troca do cateter de demora, não deve ser rotineira, portanto, não há um consenso de recomendação para troca do cateter vesical de demora, havendo alterações clínicas, incrustações ou drenagens inadequadas e episódios de infecção a troca deve ser planejada com intervalos regulares.

Tabela 1- Distribuição por indicação, tipo de cateterismo e frequência de troca

\begin{tabular}{lccc}
\hline INDICAÇÕES & CISTOSTOMIA & URETRAL & $\begin{array}{l}\text { FREQUENCIA } \\
\text { DE TROCA }\end{array}$ \\
\hline CA de Próstata & $\%$ & $\%$ & $30 / 30$ \\
Hiperplasia & 1 & 4 & $30 / 30$ \\
Infecção do Trato Urinário & 1 & 13 & $30 / 30$ \\
Bexigoma & - & 6 & $30 / 30$ \\
Hidronefrose & 1 & 3 & $30 / 30$ \\
Estenose & - & - & $30 / 30$ \\
Incontinência urinária & - & 2 & $30 / 30$ \\
\hline Total & 5 & 31 &
\end{tabular}

Fonte: Amostragem da pesquisa na unidade de atenção básica no Município de São Gonçalo no período de fevereiro de 2021.

Os traumas ocasionados pela inserção do cateter urinário muitas vezes resultando em lesões e falsos trajetos, que podem ou não ser acompanhados de uretrorragias e infecções do trato urinário; provocam manifestação dolorosa, oriunda do atrito do cateter mal lubrificado contra a mucosa uretral e/ou das manobras agressivas originárias da força aplicada na sua inserção. São comuns em pacientes do sexo masculino e atualmente podem ser consideradas as principais causas notificadas de estenose uretral (RIBEIRO,2011) . 


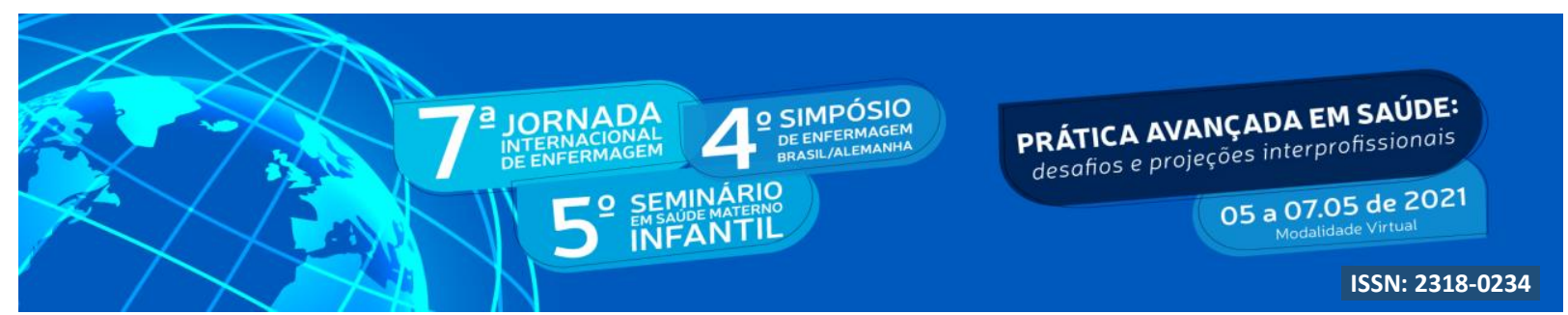

\section{CONCLUSÃO}

Este estudo mostrou que a dinâmica interativa entre a equipe multidisciplinar na atençao básica e seus pacientes favorece a promoção, prevenção e controle das infecções do trato urinário no uso de cateter de demora, contribuindo na redução de sua incidência e prevalência. Foi possível perceber que a população idosa cresceu muito nos últimos 20 anos e tornou se um problema de saúde pública, uma vez que esta população é mais vulnerável devido aos fatores determinantes e condicionantes, tais como: estilo de vida, condições sócio econômicas, e principalmente no que tange ao autocuidado. $\mathrm{O}$ abandono destes pacientes por suas famílias acarreta precaridade no cuidado.

Com o objetivo de minimizar os riscos de infecção urinária, o sistema fechado de drenagem de urina, manter a bolsa coletora em nível abaixo da inserção do cateter evitando desta forma o refluxo intravesical de urina, a higienização das mãos com água e sabão, antes e depois da manipulação da sonda e do coletor de urina e adoção de prática de segurança, são hábitos recomendados. 


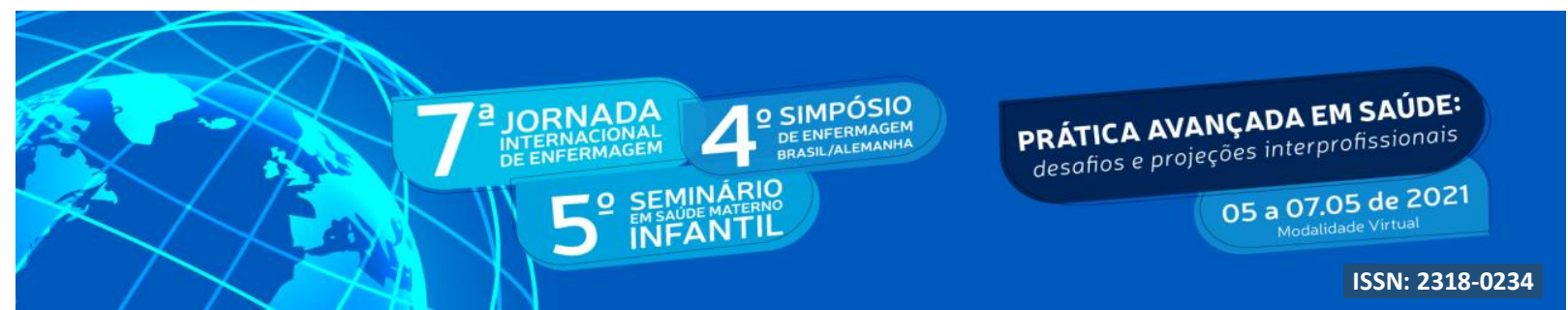

\section{REFERÊNCIAS}

ABEGG, P. T. G. M.; SILVA, L. L. Controle de infecção hospitalar em unidade de terapia intensiva: estudo retrospectivo. Semina: Ciências Biológicas e da Saúde, Londrina, v. 32, n. 1, p. 47-58, jan./jun. 2011.

BRASIL. Ministério da Saúde. Agência Nacional de Vigilância Sanitária. Medidas de prevenção de infecção relacionada à assistência à saúde. Brasília: Anvisa; 2017: http://www20.anvisa.gov.br/segurancadopaciente/images/documentos/livros/Livro4MedidasPrevencaoIRASaude.pdf

BRASIL, 2013. Resolução $\mathrm{n}^{\circ}$ 466, de 12 de dezembro de 2012. Dispõe sobre diretrizes e normas regulamentadoras de pesquisas envolvendo seres humanos. Diário Oficial [da] República Federativa do Brasil, Brasília, https://bvsms.saude.gov.br/bvs/saudelegis/cns/2013/res0466_12_12_2012.html

BRASIL. Resolução $n^{\circ}$ 510, de 07 de abril de 2016. Dispõe sobre as normas aplicáveis a pesquisas em Ciências Humanas e Sociais. Diário Oficial [da] República Federativa do Brasil, Brasília, DF, 24 maio 2016. Disponível em: <Disponível em: http://bit.ly/2fmnKeD >. Acesso em:

fev. 2021. http://bit.ly/2fmnKeD

BRASIL. Lei n 7.498, de 25 de junho de 1986. Dispõe sobre a regulamentação do exercício da Enfermagem e dá outras providências. Diário Oficial da União, Brasília, DF, 26 jun 1986. Disponível em: . Acesso em: 20 out. 2012

CARLESSO, A.; BASSO, C. A. A importância dos cuidados de Enfermagem na prevenção da infecção do trato urinário relacionada ao cateter. 2015. $32 \mathrm{f}$. Trabalho de Conclusão de Curso (Especialização em Gestão em Saúde e Controle de Infecção). Faculdade Método de São Paulo Programa. São Paulo, 2015.

CONSELHO FEDERAL DE ENFERMAGEM. Parecer Normativo para Atuação da Equipe de Enfermagem em Sondagem Vesical, anexo II, de 11 dezembro de 2013. Estabelece diretriz para atuação da equipe de enfermagem em sondagem vesical visando à efetiva segurança do paciente submetido ao procedimento.

COLOGNA AJ. Cistostomia. Medicina (Ribeirão Preto) [Internet]. Acessado em 18 de março de 2021 [citado 15 de março de 2021];44(1):57-62. Disponível em: https://www.revistas.usp.br/rmrp/article/view/47336

ERCOLE, F. F. et al. Revisão Integrativa: evidências na prática do cateterismo urinário intermitente/demora. Revista LatinoAmericana de Enfermagem, Ribeirão Preto, v. 21, n. 1, jan./fev. 2013. Disponível em: . Acesso em: http://www.scielo.br/pdf/riae/pt_v21n1a23_Acesso em 10 fevereiro. 2018.

FREITAS ERFS. Perfil e gravidade dos pacientes das unidades de terapia intensiva: aplicação prospectiva do escore APACHE II. Rev Latino-AmEnferm. 2010; 18(3):20-6. 


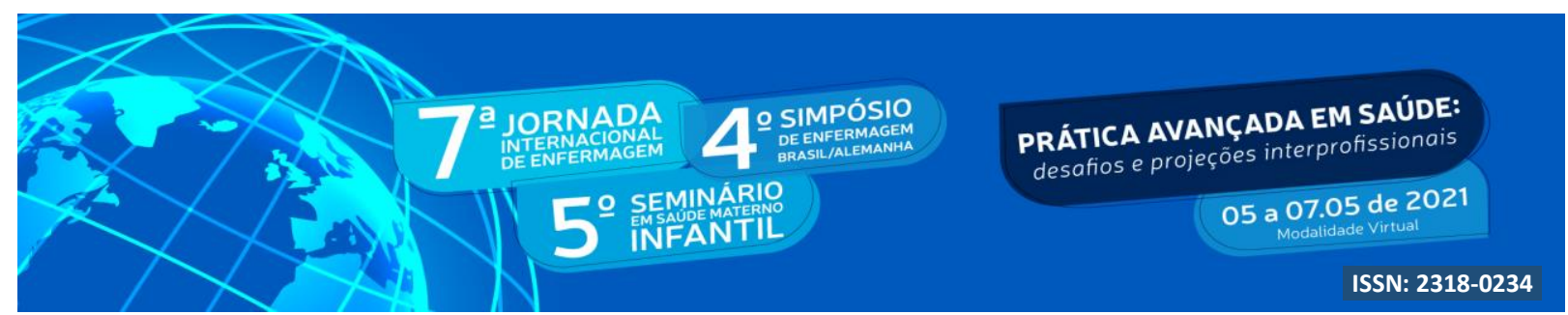

OLIVEIRA AC, CLEMENTE WT, LUCAS TC, MARTINHO GH. Infecções hospitalares e resistência microbiana em unidade de cuidados intensivos de um hospital universitário. Rev. Enferm. UERJ. 2009;17(1):96-101.

OLIVEIRA, AC, KKOVNER CT, SILVA, RS. Infecção hospitalar em unidade de tratamento intensivo de um hospital universitário brasileiro. Rev. Latino- Am. Enfermagem.2010; 18 (2): 98-104.

RIBEIRO, R. G. et al. Infecção Hospitalar do trato urinário relacionada ao cateterismo vesical de demora. Revista Científica FACS, Governador Valadares, v. 13, n. 14, 2011.

SILVA ALQC, ARAÚJO LS, SILVA ZSSB, MERCÊS PL. Práticas educativas mais utilizadas pelos enfermeiros na atenção básica: uma revisão bibliográfica. Revista Científica do ITPAC 2013;6(4):1-5. 